\title{
The influence of using fractal analysis in hybrid MLP model for short-term forecast of close prices on Warsaw Stock Exchange
}

\author{
Michał Paluch \\ Institute of Applied Computer Science, \\ Lodz University of Technology \\ 90-924 Łódź, ul. Stefanowskiego 18/22 \\ Tel. +48-533-538-113, \\ mpaluch@kis.p.lodz.pl
}

\author{
Lidia Jackowska-Strumiłło \\ Institute of Applied Computer Science, \\ Lodz University of Technology \\ 90-924 Łódź, ul. Stefanowskiego 18/22 \\ Tel. (+48) 426312750 \\ lidia_js@kis.p.lodz.pl
}

\begin{abstract}
The paper describes a new method of combining Artificial Neural Networks (ANN), technical analysis and fractal analysis for predicting share prices on the Warsaw Stock Exchange. The proposed hybrid model consists of two consecutive modules. In the first step share prices are preprocessed and calculated into moving averages and oscillators. Then, in the next step, they are given to the ANN inputs, which provides the closing values of the asset for the next day. ANN of Multi-Layer Perceptron (MLP) type, and fractal analysis are applied. The hybrid model combining ANN with technical and fractal analysis is compared with hybrid model combining ANN with technical analysis. The obtained results indicate that hybrid model combined with fractal analysis is more accurate and stable in the long run than the hybrid model.
\end{abstract}

\section{INTRODUCTION}

$\mathrm{A}$ S TRADING systems are becoming more complex, there is also a growing interest in applying artificial intelligence methods, i.e. artificial neural networks [28; 24; 27], fuzzy logic [31] or increasingly popular fractal analysis to support stockbrokers and investors in their decisions aimed at maximizing profits. The financial market, which uses the most advanced IT solutions, provides a variety of products to meet this goal. From all of them, the most popular are financial instruments offered by the Stock Exchange, which may be very profitable, but with a big profit there is also a risk of losing all assets [5]. Recently, artificial neural network (ANN) are gaining in importance for stock quotes time series prediction. The most commonly used artificial neural networks to predict trading signals are the feed-forward neural networks (FNN) [10, 24, 28, 32] of Multi-Layer Perceptron (MLP) type, but also new approaches and ANN structures, like for e.g.: dynamic artificial neural network [11], Probabilistic Neural Networks (PNN) [27], State Space Wavelet Network (SSWN) [3] or a neural-wavelet analysis [14] are still subject of scientific studies. The most common use of ANN on Stock Exchange is: prediction of future stock market indices [3, 24, 26], exchange rates [27], share prices, etc.
Nowadays, hybrid modelling approach is used more often by many researchers. The aim of using hybrid models for Stock Exchange shares forecasting is to reduce risk of failure and obtain the results which are more accurate. Typically, this is done because the underlying process cannot easily be determined. The motivation for combining models comes from the assumption that either one cannot identify the true data generating process or that a single model may not be sufficient to identify all the characteristics of the time series. Different hybrid models were used for this purpose. Khashei and Bijari [18] proposed a new combination of ARIMA and ANN approaches, in which a time series predicted by ANN is considered as nonlinear function of several past observations and random errors. This model was more accurate than ARIMA, ANN and Zhang models [33].

Güresen and Kayakutlu [13] investigated hybrid neural networks which used generalized autoregressive conditional heteroscedasticity $(\mathrm{GARCH})$ and exponential generalized autoregressive conditional heteroscedasticity (EGARCH) to extract new ANN input variables. They also tested combinations of statistical GARCH and EGARCH models with different neural networks [12], i.e. MLP and DAN2 dynamic artificial neural network developed by Ghiassi and Saidane [11]. The lowest error for the testing data in prediction of NASDAQ index was achieved by the use of DAN2 network and next by MLP network. Hybrid GARCH-ANN and EGARCH-ANN models ensured worse results, contrary to expectations.

Majhi, Panda, and Sahoo [19] compared functional link artificial neural network (FLANN), cascaded functional link artificial neural network (CFLANN), and LMS model and also observed that the CFLANN model performs the best prediction of exchange rates followed by the FLANN and the LMS models. Interesting hybrid approach combining technical analysis and ANN for trading systems development was proposed by Witkowska and Marcinkiewicz [29]. 15 trading systems were designed for the Warsaw Stock Exchange future contracts and compared. Five strategies of investment decisions were investigated, including four based on 
technical analysis indicators, which were combined with three methods of the WIG20 index future closing prices forecasting. The final conclusion was that the combination of the technical analysis and artificial intelligence in order to gain profit from trading on the Stock Exchange can bring much better investment results than trade in the traditional way. The best results for the WIG20 index time series forecasting were obtained by the use of ANN of MLP type with a set of about 30 input variables, which were divided in 3 subsets: variables related to the WIG20 index Close prices, variables related to the technical analysis indicators, variables related to the external factors.

In this paper, a new hybrid analytical and ANN model is proposed, which combines ANN with technical and fractal analysis. Previously, the hybrid models combining technical analysis with ANN without fractal analysis were compared with purely ANN based approach [22].

It will be shown that hybrid ANN model which uses technical and fractal analysis is more stable in the long run than hybrid ANN model using only technical analysis and that fractal analysis reduces the error of shares forecasting.

\section{TECHNICAL ANALYSIS INDICATORS}

Technical analysis indicators are used to determine trend of the market, the strength of the market, and the direction of the market. Some technical analysis indicators can be quantified in the form of an equation or algorithm. Others can show up as patterns (e.g., head and shoulders, trend lines, support, and resistance levels). At some point, the technical analyst will receive a signal. This signal is the result of one technical analysis indicator or a combination of two or more indicators. The signal indicates to the technical analyst a course of action whether to buy, sell, or hold [29].

The most commonly used technical analysis indicators are moving averages and oscillators [20], which were selected for the proposed approach. These include the following:

- Moving averages:

a. Expotential (5-, 10-, 20-days) - EMA (Expotential Moving Average)

$\mathrm{EMA}_{\mathrm{N}, \mathrm{C}}(\mathrm{k})=\frac{\mathrm{C}(\mathrm{k})+\mathrm{aC}(\mathrm{k}-1)+\mathrm{a}^{2} \mathrm{C}(\mathrm{k}-2)+\ldots+\mathrm{a}^{\mathrm{N}-1} \mathrm{C}(\mathrm{k}-\mathrm{N}+1)}{1+\mathrm{a}+\mathrm{a}^{2}+\ldots+\mathrm{a}^{\mathrm{N}-1}}$

where:

a- coefficient

b. Envelopes (3\% error with 20 -days average)
- Oscillators

a. ROC - Rate of Change (5-, 10-, 20-days) - determines the rate of price changes in a given period (usually 10 days)

$$
\mathrm{ROC}_{\mathrm{N}}(\mathrm{k})=\mathrm{C}(\mathrm{k}) / \mathrm{C}(\mathrm{k}-\mathrm{N})
$$

b. RSI - Relative Strength Index - i.e. the measure of overbought / oversold market. It assumes values in the range of $0-100$. For values greater than 70 it is considered that the market is buyout. When oscillator values are below 30, it signifies that market is sold out. In the case of periods of strong trends it is assumed that the market is buyout when RSI> 80 (at the time of a bull market) and sold out for RSI $<20$ (during a bear market).

$$
\begin{array}{r}
\text { For: } \\
\mathrm{C}(\mathrm{k})>\mathrm{C}(\mathrm{k}-1), \quad \mathrm{U}(\mathrm{k})=\mathrm{C}(\mathrm{k})-\mathrm{C}(\mathrm{k}-1) \\
\mathrm{C}(\mathrm{k})<\mathrm{C}(\mathrm{k}-1), \quad \mathrm{D}(\mathrm{k})=|\mathrm{C}(\mathrm{k})-\mathrm{C}(\mathrm{k}-1)| \\
\mathrm{RSI}(\mathrm{k})=100-\left[\frac{100}{1+\frac{\mathrm{EMA}_{\mathrm{N}, \mathrm{U}}(\mathrm{k})}{\mathrm{EMA}_{\mathrm{N}, \mathrm{D}}(\mathrm{k})}}\right]
\end{array}
$$

where

$\mathrm{U}(\mathrm{k})$ - average increase in the k-th day

$\mathrm{D}(\mathrm{k})$ - average decrease in the k-th day

c. Stochastic oscillator $(\mathrm{K} \% \mathrm{D})$ - determines the relation between the last closing price and the range of price fluctuations in the given period. The result belongs to the range of $0-100 . \mathrm{K} \% \mathrm{D}>70$ is interpreted as the closing price near the top of the range of its fluctuations, and $\mathrm{K} \% \mathrm{D}<30$ points to the fact that prices are shaping near the lower limit of that range.

$$
\mathrm{K} \% \mathrm{D}(\mathrm{k})=100 *\left[\frac{\mathrm{C}(\mathrm{k})-\mathrm{L}(14)}{\mathrm{H}(14)-\mathrm{L}(14)}\right]
$$

where:

$\mathrm{L}(14)$ - the lowest price from last fourteen days $\mathrm{H}(14)$ - the highest price from last fourteen days

d. Moving Average Convergence/Divergence (MACD) is the difference between two moving averages. On the graphs, it usually occurs with 10- day, exponential moving average (called the signal line). The intersection of the signal line (SL) with the MACD line 
coming from the bottom is a buying signal, while with the line from the top - a selling signal.

$$
\begin{array}{r}
\operatorname{MACD}(\mathrm{k})=\mathrm{EMA}_{12, \mathrm{C}}(\mathrm{k})-\mathrm{EMA}_{26, \mathrm{C}}(\mathrm{k}) \\
\operatorname{SL}(\mathrm{k})=\mathrm{EMA}_{9, \mathrm{MACD}}(\mathrm{k})
\end{array}
$$

e. Accumulation/Distribution $(\mathrm{AD})$ indicator presents whether price changes are accompanied by increased accumulation and distribution movements.

$$
\mathrm{AD}(\mathrm{k})=\mathrm{V}(\mathrm{k}) * \frac{\mathrm{C}(\mathrm{k})-\mathrm{L}(\mathrm{k})-[\mathrm{H}(\mathrm{k})-\mathrm{C}(\mathrm{k})]}{\mathrm{H}(\mathrm{k})-\mathrm{L}(\mathrm{k})}
$$

where:

$\mathrm{V}(\mathrm{k})$ - total number of shares which were rotated on $\mathrm{k}$ day

\section{f. Bollinger Oscillator}

Its construction is based on Bollinger bands. Bollinger oscillator informs when market is overbought or oversold.

$$
\mathrm{BOS}_{\mathrm{k}}=\frac{\mathrm{C}_{\mathrm{k}+(\mathrm{N}-1)}-\mathrm{SMA}_{\mathrm{v}}(\mathrm{C}(\mathrm{k}))}{\mathrm{S} \tan \operatorname{dardDev}(\mathrm{k})}
$$

For the purpose of counting highest errors between predicted value and real CLOSE value, the following formulas have been used:

a. The highest prediction error per month

$\mathrm{E}_{\max }=$ Highest difference between real CLOSE value and predicted by ANN value per month

b. Arithmetical mean of $E_{\max }$ value per tested period of time

$$
\overline{\mathrm{E}_{\max }}=\frac{1}{\mathrm{~N}} \sum_{\mathrm{i}=1}^{\mathrm{N}} \mathrm{E}_{\max _{\mathrm{i}}}
$$

\section{FRACTAL ANALYSIS}

Recently it can be seen that fractal market hypothesis is constantly expanding. It was presented for the first time by Peters [7] in 1994, and is based on chaos theory [8]. Fractal shapes can be formed in many ways. The simplest is a multiple iteration of generating rule (e.g. the Koch curve or Sierpinski triangle). They are generated in deterministic way and all have fractal dimension. There are also random fractals, like stock prices, which are generated with the use of probability rules.

Performing a fractal analysis is based on identification of fractal dimension. To do this, chart has to be divided into $\mathrm{N}$ small elements with $\mathrm{S}$ surface. The relationship between the number of objects $\mathrm{N}_{1}$ and $\mathrm{N}_{2}$, which are used to cover the first and second graph with objects of surface size, respectively $S_{1}$ and $S_{2}$, describes the relationship [9]:

$$
\begin{gathered}
\frac{\mathrm{N}_{2}}{\mathrm{~N}_{1}}=\left(\frac{\mathrm{S}_{1}}{\mathrm{~S}_{2}}\right)^{\mathrm{D}} \\
\mathrm{D}=\frac{\log \left(\frac{\mathrm{N}_{1}}{\mathrm{~N}_{2}}\right)}{\log \left(\frac{\mathrm{S}_{1}}{\mathrm{~S}_{2}}\right)}
\end{gathered}
$$

where:

D - fractal dimension

In order to measure fractal dimension on stock exchange, we need to divide the given period of time by two. For each period, share prices curve have to be divided into $\mathrm{N}$ pieces. It can be done by dividing the subtraction result of highest and lowest value on graph in given period of time, by this period:

$$
\begin{aligned}
& \mathrm{N}_{1 \mathrm{~T}}(\mathrm{k})=\frac{\mathrm{H}_{\mathrm{T}}(\mathrm{k})-\mathrm{L}_{\mathrm{T}}(\mathrm{k})}{\mathrm{T}} \\
& \mathrm{N}_{2 \mathrm{~T}}(\mathrm{k})=\frac{\mathrm{H}_{2 \mathrm{~T}}(\mathrm{k})-\mathrm{L}_{2 \mathrm{~T}}(\mathrm{k})}{\mathrm{T}} \\
& \mathrm{N}_{0-2 \mathrm{~T}}(\mathrm{k})=\frac{\mathrm{H}_{0-2 \mathrm{~T}}(\mathrm{k})-\mathrm{L}_{0-2 \mathrm{~T}}(\mathrm{k})}{2 \mathrm{~T}} \\
& \mathrm{D}=\frac{\log \left(\frac{\mathrm{N}_{1 \mathrm{~T}}+\mathrm{N}_{2 \mathrm{~T}}}{\mathrm{~N}_{(0-2) \mathrm{T}}}\right)}{\log \left(\frac{2 \mathrm{~T}}{\mathrm{~T}}\right)}=\frac{\log \left(\mathrm{N}_{1 \mathrm{~T}}+\mathrm{N}_{2 \mathrm{~T}}\right)-\log \left(\mathrm{N}_{(0-2) \mathrm{T}}\right)}{\log (2)}
\end{aligned}
$$

where:

$\mathrm{H}_{\mathrm{T}}(\mathrm{k})$ - the highest share price in the first period $\mathrm{T}$

$\mathrm{H}_{2 \mathrm{~T}}(\mathrm{k})$ - the highest share price in the second period (from $\mathrm{T}$ till 2T)

$\mathrm{H}_{0-2 \mathrm{~T}}(\mathrm{k})$ - the highest share price in $2 \mathrm{~T}$ period

$\mathrm{L}_{\mathrm{T}}(\mathrm{k})$ - the lowest share price in the first period $\mathrm{T}$

$\mathrm{L}_{2 \mathrm{~T}}(\mathrm{k})$ - the lowest share price in the period from $\mathrm{T}$ till $2 \mathrm{~T}$

$\mathrm{L}_{0-2 \mathrm{~T}} \mathrm{~T}(\mathrm{k})$ - the lowest share price in $2 \mathrm{~T}$ period

Fractal dimension is used in this paper in Fractal Moving Average (FRAMA). This moving average is based on Expotential Moving Average (eq. 1) where a coefficient is constructed with the use of fractal dimension: 


$$
\mathrm{a}=\exp (-4.6 *(\mathrm{D}-1))
$$

\section{APPLICATION OF TECHNICAL ANALYSIS AND ANN FOR PREDICTION OF CLOSING PRICES}

Closing price of the asset for the next day is one of the most important parameters for investors, who plan to make transactions at the Stock Exchange. In this work a hybrid approach combining technical analysis with ANN and a hybrid approach combining technical and fractal analysis with ANN is being compared. The main idea of the proposed method is shown in Fig. 1. Technical analysis methods are used to calculate moving averages and oscillators, which are important market indicators. These are the inputs of ANN, which predicts the CLOSE value of the next day. The aim of this paper was to investigate if the proposed data preprocessing with market indicators calculation connected with the use of fractal dimension would improve the ANN effectiveness in the CLOSE value prediction.

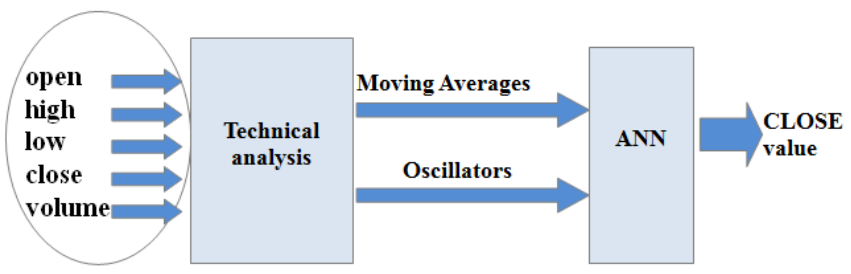

Fig. 1. Processing scheme for predicting course of a CLOSE value for the next day [19]

The programming application was designed and implemented for the data collecting and pre-processing. The calculated moving averages and oscillators were used for neural network training and testing. Feedforward networks of Multi-Layer Perceptron (MLP) type [25] trained with the Levenberg-Marquardt algorithm were used for the CLOSE value prediction. The choice of the ANN input variables presented in this paper was made based on the experience and knowledge of a stock market expert.

The model structure was overtaken from the Authors' previous experience with hybrid analytical-neural approach in engineering applications, which ensured better modelling results as pure ANN solutions $[16,17]$. Thanks to the data preprocessing the designed model is efficient and ANN has a simple structure.

\section{EXPERIMENTAL RESEARCH}

Research was conducted for 2 exemplary companies (Vistula SA and Budimex SA) appearing on the Warsaw stock market since 2.01.1996 until 14.04.2014. The aim of the research was to compare the results of short-term prediction of two hybrid models. Their hybridity differs in terms of the technical analysis indicators and fractal moving averages used as ANN inputs (Table II). The research was performed with the use of Java and Encog 3.2 library, creating ANN of MLP type. Each network consists of an input, hidden and output layer. A common feature of all of the tested network architectures is a small number of input nodes and neurons in the hidden layer, and only one neuron in the output layer. Too many neurons would increase the network training error and could cause learning time extension [5]. The relations between the number of input nodes and the number of neurons in the hidden layer were tested for the combinations shown in Table 1.

Table I

COMBINATIONS OF THE TESTED MLP ARCHITECTURES

\begin{tabular}{|c|c|c|}
\hline \multirow{2}{*}{$\begin{array}{c}\text { Input } \\
\text { layer }\end{array}$} & $\begin{array}{c}\text { Hidden } \\
\text { layer }\end{array}$ & $\begin{array}{c}\text { Output } \\
\text { layer }\end{array}$ \\
\hline \multirow{2}{*}{$\mathrm{n}$} & $\mathrm{n}+1$ & \multirow{2}{*}{1} \\
\cline { 2 - 2 } & $1.5 \mathrm{n}$ & \\
\cline { 2 - 2 } & $2 \mathrm{n}-1$ & \\
\cline { 2 - 2 } & $2 \mathrm{n}+1$ & \\
\hline
\end{tabular}

where $n-$ number of neurons ( $n=4,5,6$ neurons)

Market indicators for the input data were selected based on the literature $[1,4,10,20,32]$ and an advice of a stock market expert. ANN training was performed according to the following rules:

1. All entered data were normalized using the following heuristic formula:

$$
\left(\text { Value/Value }_{\max }\right) * 0.8+0.1
$$

2. The results of each company were divided into two groups: learning data and testing data in the proportion 70:30 [19]

3. Neural networks were taught with the LevenbergMarquardt algorithm [16, 23].

4. For each ANN architecture and each set of input data, eight neural networks were trained, and the ANN with the smallest medium square error (MSE) for the testing data has been selected as the best one.

The hybrid model structures combining MLP with technical analysis with or without using the fractal dimension, and also the obtained results are gathered in Table II. Technical analysis indicators, which are ANN inputs are listed in the second column. The MLP (7-15-1) structure means, that it consists of seven input nodes, fifteen neurons in a hidden layer and one neuron in an output layer.

The results of short-term forecast of CLOSE value of Vistula SA shares predicted with the use of Hybrid MLP (7-15-1) model (no. 1 in Table 2) and Hybrid MLP (7-15-1) model with fractal dimension (no. 2 in Table 2) are shown in 
figures 2 and 3. In the first case (Fig. 2) share prices of Vistula SA are in horizontal trend and in the second period

of time (Fig. 3) in downward trend.

Table II

HYBRID MODELS WITH SELECTED ANN STUCTURES, FOR WHICH THE BEST RESULTS WERE ACHIEVED

\begin{tabular}{|c|c|c|c|c|c|c|}
\hline No. & $\begin{array}{l}\text { ANN } \\
\text { inputs }\end{array}$ & $\begin{array}{c}\text { Model } \\
\text { structure }\end{array}$ & $\begin{array}{l}\text { Transfer } \\
\text { function }\end{array}$ & Periods & $\begin{array}{c}\text { Training } \\
\text { error }\end{array}$ & $\begin{array}{c}\text { Testing } \\
\text { error }\end{array}$ \\
\hline \multirow{7}{*}{1.} & RSI & \multirow{7}{*}{$\begin{array}{c}\text { Hybrid } \\
\operatorname{MLP}(7-15-1)\end{array}$} & \multirow{7}{*}{ sigmoidal } & \multirow{7}{*}{7000} & \multirow{7}{*}{0.0327} & \multirow{7}{*}{0.023} \\
\hline & MACD & & & & & \\
\hline & $\mathrm{AD}$ & & & & & \\
\hline & $\mathrm{BO}$ & & & & & \\
\hline & $\mathrm{EMA}_{\mathrm{k}-4}$ & & & & & \\
\hline & $\mathrm{EMA}_{\mathrm{k}-9}$ & & & & & \\
\hline & ROC & & & & & \\
\hline \multirow{7}{*}{2.} & RSI & \multirow{7}{*}{$\begin{array}{c}\text { Hybrid } \\
\text { MLP(7-15-1) }\end{array}$} & \multirow{7}{*}{ sigmoidal } & \multirow{7}{*}{7000} & \multirow{7}{*}{0.0312} & \multirow{7}{*}{0.021} \\
\hline & MACD & & & & & \\
\hline & $\mathrm{AD}$ & & & & & \\
\hline & $\mathrm{BO}$ & & & & & \\
\hline & FRAMA $_{k-4}$ & & & & & \\
\hline & FRAMA $_{k-9}$ & & & & & \\
\hline & ROC & & & & & \\
\hline
\end{tabular}

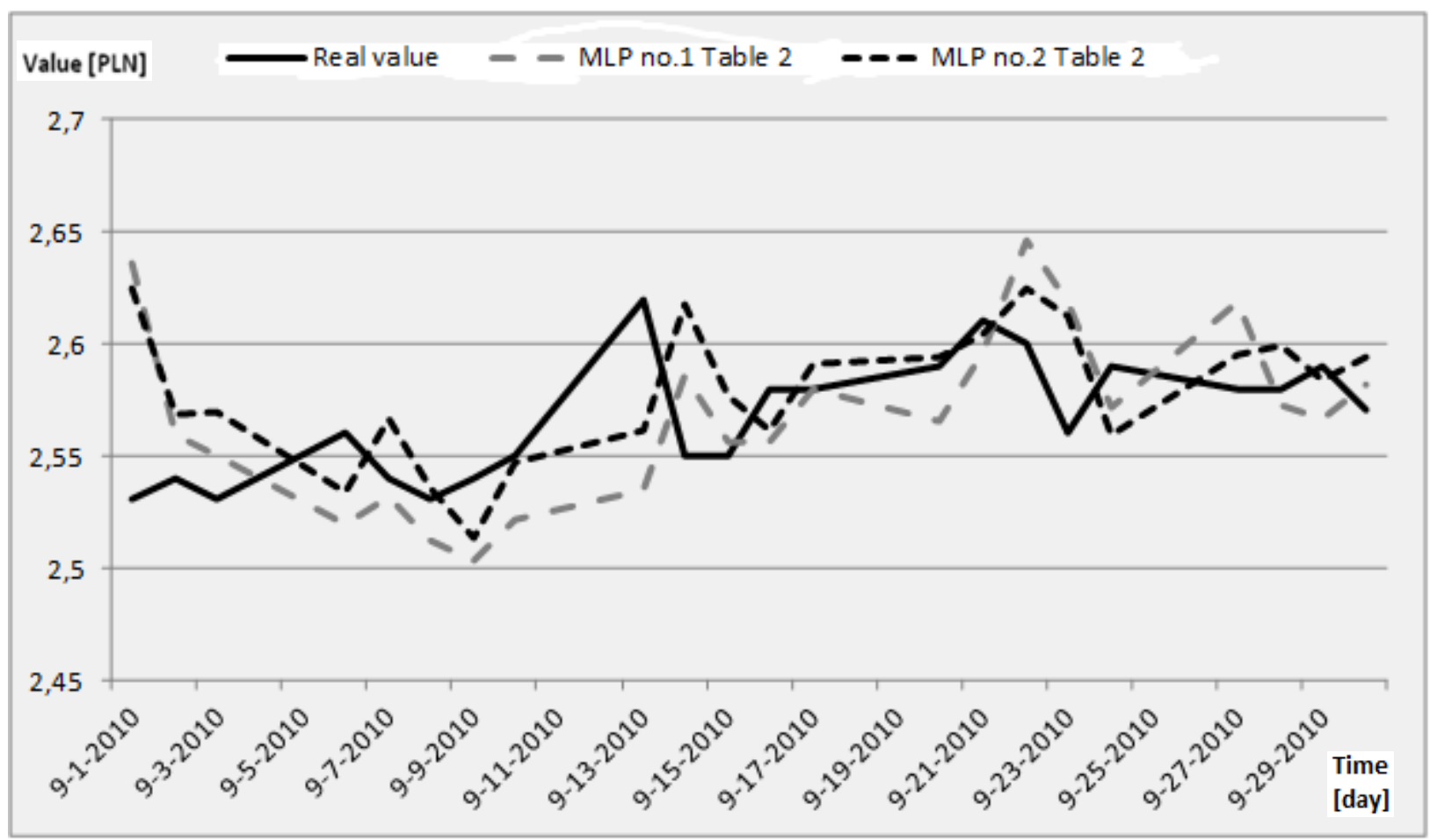

Fig. 2. Short-term forecast of two hybrid models with MLP (7-15-1) network: no. 1 in Table 2 and no. 2 in Table 2 (with fractal dimension) and real CLOSE value of Vistula SA shares in September 2010. 


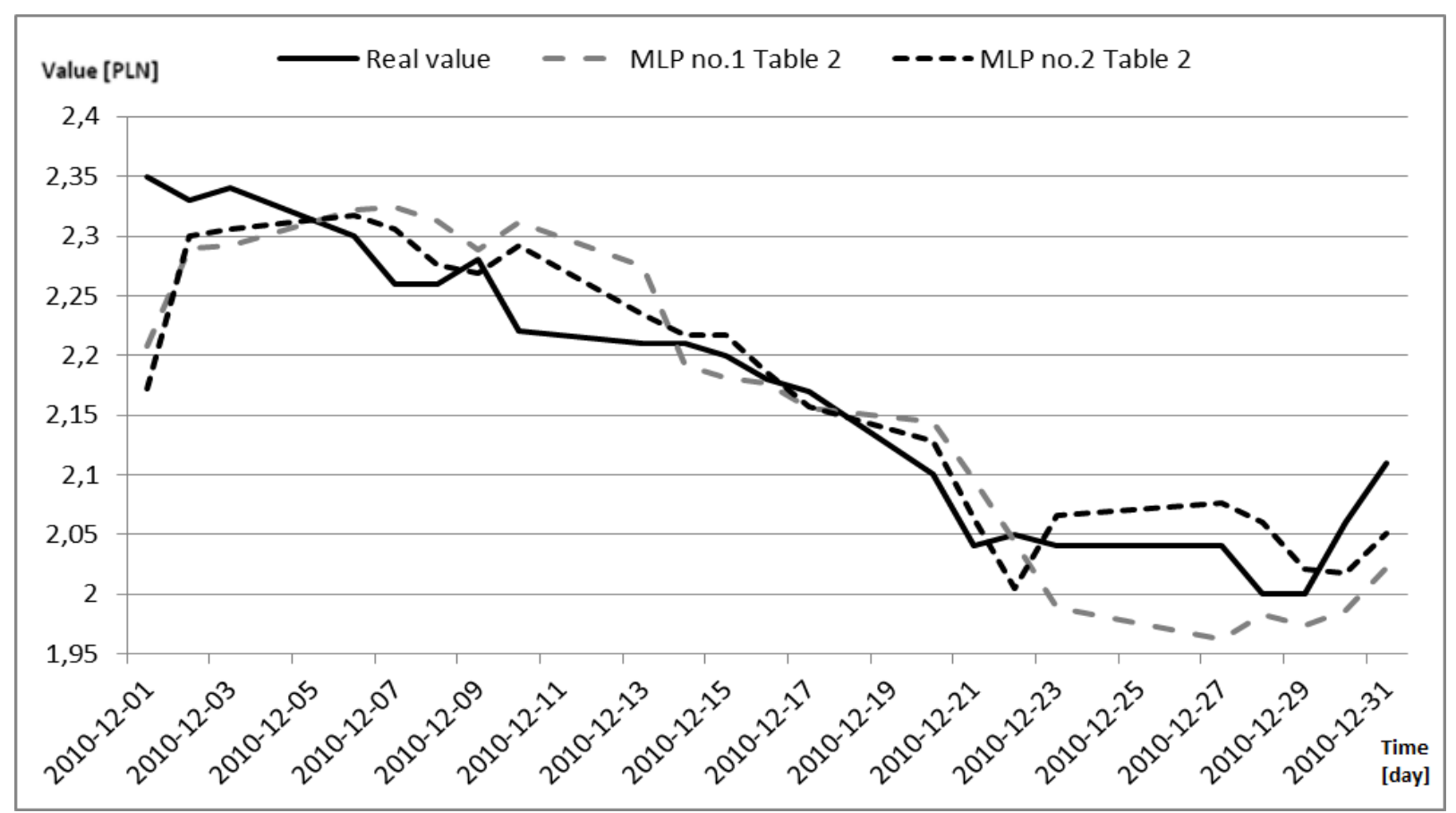

Fig. 3 Short-term forecast of two hybrid models with MLP (7-15-1) network: no. 1 in Table 2 and no. 2 in Table 2 (with fractal dimension) and real CLOSE value of Vistula SA shares in December 2010.

Comparison of the obtained results shows that prediction of hybrid model with FRAMA (no. 2 in Table 2) was more accurate while share prices were in distinct trend. Example is being shown in figure 3, where Vistula SA shares have been in downward trend on December 2010. On the other hand, both hybrid models provide similar results when share prices are in horizontal trend, which can be seen in figure 2 .

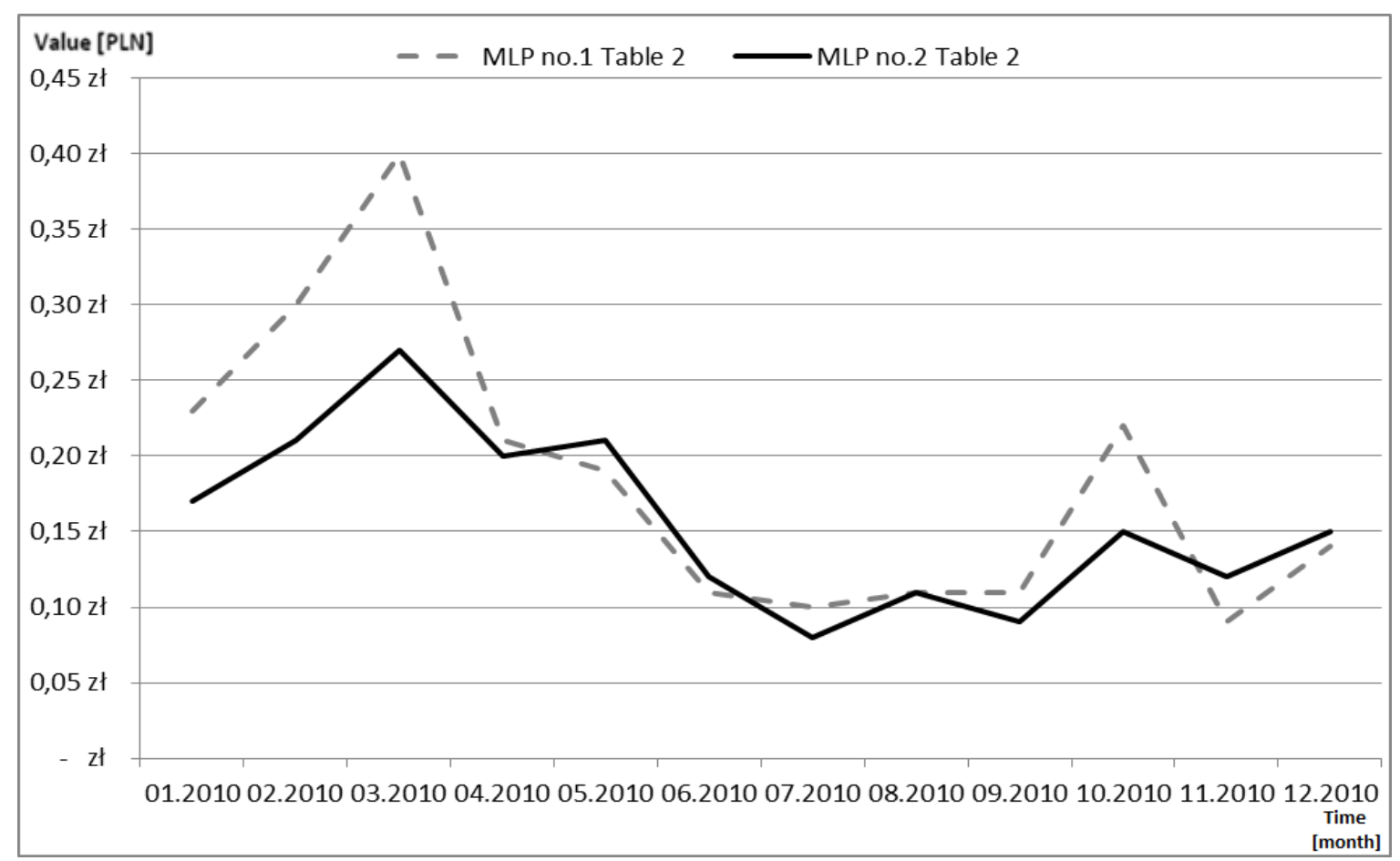

Fig. 4. Comparison of $\mathrm{E}_{\max }$ values between hybrid model with hybrid MLP (7-15-1) (no. 1 in Table 2) and hybrid MLP (7-15-1) (no. 2 in Table 2) for Vistula SA 
To assess which model is more accurate and stable, the maximum absolute errors $\mathrm{E}_{\max }$ of prediction in the period of one year were compared. Maximum absolute error was calculated as the maximum absolute difference between true CLOSE value and the model prediction for each month.
Summary of the results for hybrid models with and without FRAMA are presented in figures 4 and 5. Similar results have been achieved for Vistula SA (Fig. 4) and for Budimex SA (Fig. 5). For a comparison results are shown for the same period of time.

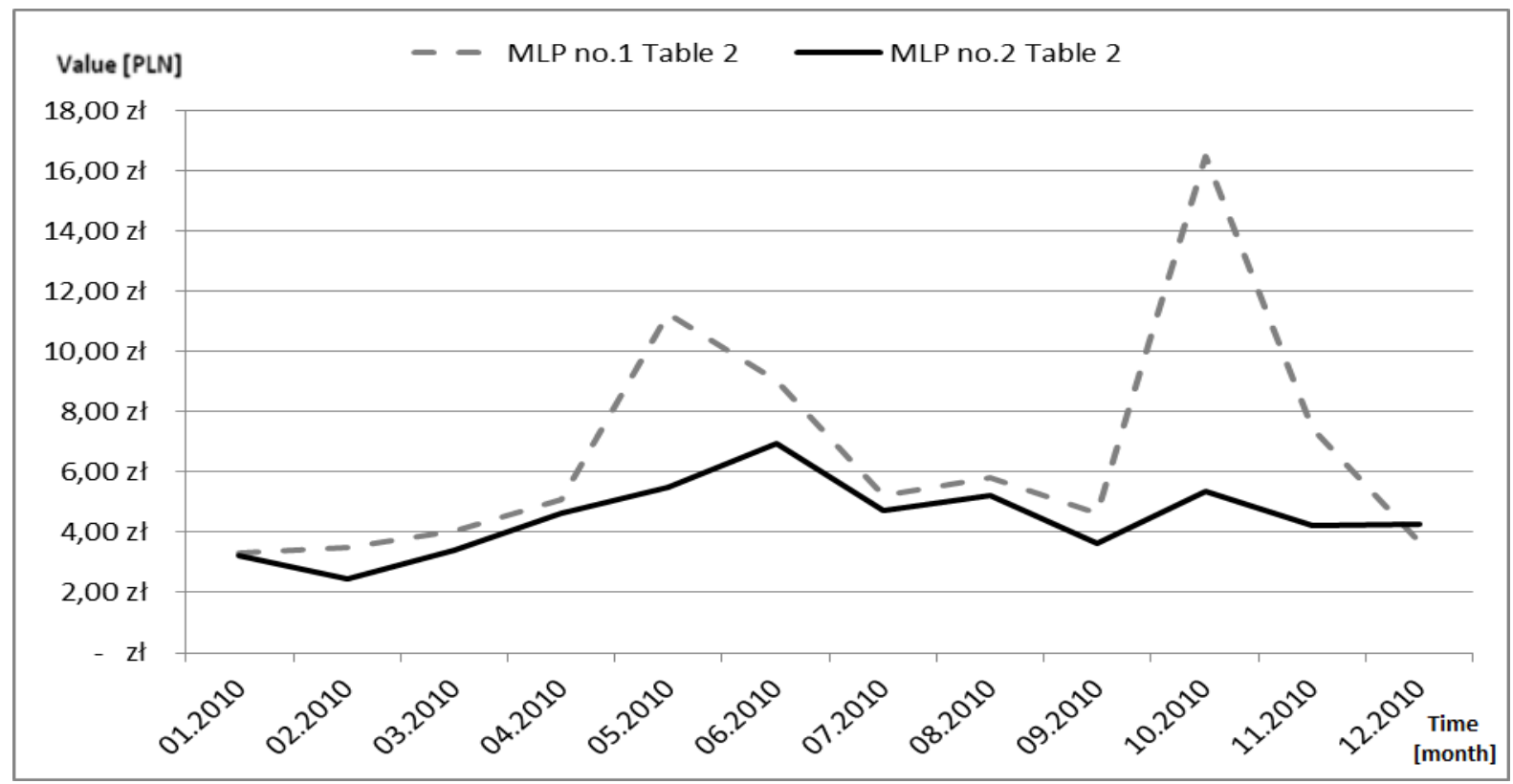

Fig. 5. Comparison of $E_{\max }$ values between hybrid model with hybrid MLP (7-15-1) (no. 1 in Table 2) and hybrid MLP (7-15-1) (no. 2 in Table 2) for Budimex SA

\section{CONCLUSIONS}

The obtained experimental results for Vistula SA and for Budimex SA suggest that the hybrid analytical-neural model combined with the fractal analysis yields better approximation of the real shares values than the hybrid model without fractal analysis. Comparison of maximum error $\mathrm{E}_{\max }$ values for two hybrid models: with and without fractal analysis (no. 2 and 1 in table 2), during the audited period from January 2010 to December 2010, allows to conclude that the proposed prediction hybrid model of hybrid ANN with fractal moving average is more stable and accurate. Thus, the more stable hybrid model reduces the probability of influence of false signals coming from the market in decision-making process, simultaneously increasing potential profits.

Finally, the results lead also to the conclusion that the proposed hybrid models forecast correct direction of CLOSE price changes. Therefore, they can be used as a basis for the decision-making system, which would be used to support investor decisions on the Warsaw Stock Exchange.

\section{REFERENCES}

[1]Bensignor R.: New Concepts in Technical Analysis. Wig-Press, Warsaw 2004 (in Polish).

[2]Box G. E. P., \& Jenkins G. M. (1976). Time Series
Analysis. Forecasting and control. Holden-Day Inc., San Francisco, California, USA.

[3]Brdyś M. A., Borowa A., Idźkowiak P., Brdyś M. T.: Adaptive Prediction of Stock Exchange Indices by State Space Wavelet Networks. Int. J. Appl. Math. Comput. Sci., 2009 , Vol. 19 , No. 2 , 337-348. DOI: 10.1.1.390.8001

[4]Bulkowski Thomas N., Formation Analysis on Stock Charts. Linia, Warsaw 2011 (in Polish)

[5]Dębski W.: Financial Market and it mechanisms. PWN, Warsaw 2010 (in Polish)

[6]Dourraa H., Siyb P. (2002). Investment using technical analysis and fuzzy logic. Fuzzy Sets and Systems, 127, 221-240.

[7]Drabik E.: Applications of game theory to invest in securities, Wydawnictwo Uniwersytetu w Białymstoku, Bialystok 2000. (in Polish)

[8]Ehlers J.: Fractal Adaptive Moving Average", Technical Analysis of Stock \& Commodities" October 2005.

[9]Ehlers J.: "Cybernetics Analysis For Stocks And Futures", John Wiley \& Sons, New York 2004.

[10] Gately E. (1995). Neural Networks for Financial Forecasting, New York: Wiley. 
[11] Ghiassi M., Saidane H., Zimbra D. K.: Dynamic artificial neural network model for forecasting time series events. International Journal of Forecasting, 2005, Vol. 21, pp. 341-362. DOI: DOI:10.1016/j.ijforecast.2004.10.008

[12] Güresen E., Kayakutlu G.: Forecasting Stock Exchange Movements Using Artificial Neural Network Models and Hybrid Models. In IFIP International Federation for Information Processing, 2008, Volume 288; Intelligent Information Processing IV; Zhongzhi Shi, E. MercierLaurent, D. Leake; (Boston: Springer), pp. 129-137.

[13] Güresen E., Kayakutlu G., Daim T. U.: Using artificial neural network models in stock market index prediction. Expert Systems with Applications, 2011, Vol. 38, pp. 10389-10397. DOI: 10.1016/j.eswa.2011.02.068

[14] Hajto P. (2012). A Neural Economic Time Series Prediction with the Use of a Wavelet Analysis. Schedae Informaticae, 11, 115-132.

[15] Hamzacebi, C., Akay, D., \& Kutay, F. (2009). Comparison of direct and iterative artificial neural network forecast approaches in multiperiodic time series forecasting. Expert Systems with Applications, 36, 3839-3844. DOI: 10.1016/j.eswa.2008.02.042

[16] Jackowska-Strumiłło L.: Hybrid Analytical and ANN-based Modelling of Temperature Sensors Nonlinear Dynamic Properties, The $6^{\text {th }}$ International Conference on Hybrid Artificial Intelligence Systems, HAIS 2011, Wroclaw, Poland, 23-25 May, Lecture Notes in Artificial Intelligence, LNAI 6678, 2011, Springer-Verlag, Part I, pp. 356-363. DOI: $10.1007 / 978-3-642-21219-245$

[17] Jackowska-Strumiłło L., Jackowski T., Chylewska B., Cyniak D. Application of hybrid neural model to determination of selected yarn parameters. Fibres \& Textiles in Eastern Europe, ISSN 1230-3666, 1998, Vol. 6, Nr 4 (23), pp. 27-32.

[18] Khashei, M., \& Bijari, M. (2010). An artificial neural network (p, d, q) model for timeseries forecasting. Expert Systems with Applications, 37(1), 479-489. DOI: 10.1016/j.eswa.2009.05.044

[19] Majhi, R., Panda, G., \& Sahoo, G. (2009). Efficient prediction of exchange rates with low complexity artificial neural network models. Expert Systems with Applications, 36, 181-189. DOI: 10.1016/j.eswa.2007.09.005

[20] Murphy J. J.: Technical Analysis of Financial Markets. Wig-Press, Warsaw, 2008 (in Polish).
[21] Narendra K. S., Parthasarathy K.: Identification and control of dynamics systems using neural networks, IEEE Transactions on Neural Networks, 1990, vol.1, no. 1, pp. 4-27 DOI: 10.4236/ica.2011.23021

[22] Paluch M., Jackowska-Strumiłło L.: Prediction of closing prices on the Stock Exchange with the use of artificial neural networks. Image Processing \& Communication, 2012, Vol. 17, No. 4, pp. 275-282.

[23] Rutkowski L.,: Methods and Techniques of Artificial Intelligence. PWN, Warsaw 2009 (in Polish)

[24] Sutheebanjard, P., Premchaiswadi, W.: Stock Exchange of Thailand Index Prediction Using Back Propagation Neural Networks. In: Proc. of the Second International Conference on Computer and Network Technology (ICCNT), 2010, Bangkok, pp. 377-380. DOI: 10.1109/ICCNT.2010.21

[25] Tadeusiewicz R.: Artificial Neural Networks. Warsaw 1993 (in Polish).

[26] Tadeusiewicz R.: Discovering Neural Networks. Cracow 2007 (in Polish).

[27] Tilakaratne C. D., Morris S. A., Mammadov M. A., Hurst C. P. (2007). Predicting Stock Market Index Trading Signals Using Neural Networks. In: Proc. of the 14th Annual Global Finance Conference (GFC 2007), Melbourne, Australia, pp. 171-179 (Sep. 2007)

[28] Witkowska D.: Artificial Neural Networks and statistical methods. Selected financial issues, C. H. Beck, Warsaw 2002, (in Polish)

[29] Witkowska D., \& Marcinkiewicz E. (2005). Construction and Evaluation of Trading Systems: Warsaw Index Futures. International Advances in Economic Research, 11, 83-92. DOI: 10.1007/s11294004-7496-7

[30] Zaremba A.: Stock Exachange, 2010 (in Polish)

[31] Zhou X. S., Dong M. (2004). Can fuzzy logic make technical analysis 20/20? Financial Analyst Journal, 60, 54-75. DOI: 10.2469/faj.v60.n4.2637

[32] Zieliński J.: Intelligent management systems - theory and practice. Warsaw 2000 (in Polish).

[33] Zhang, G. P. (2003). Time series forecasting using a hybrid ARIMA and neural network model. Neurocomputing, 50, 159-175. 